these values a circus movement could not establish itself in a ring of muscle of less than 150 to 200 millimetres circumference. But it is known that much smaller circuits than these become established. What is the reason? The reasen is: that. when the auricle flutters, the refractory period is reduced; - also the rate of travel is usually reduced. These reductions both occur in response to an increased rate of beating such as prevails in flutter. Both changes facilitate the establishment of relatively. short circus morements. The precise relations of the three controlling factors have now received close investigation. They are variable in different circumstances, but may be illustrated by a type experiment. A dog's auricle is fluttering at a rate of 500 per minute. Each circuit is completed in 0.12 of a second. The circuit has a length of 60 millimetres. The rate of travel is not 1,000 millimetres per second, but 500 millimetres per second. The rate of travel is but one-half the natural rate; that is so because the rate of beating is so high that the muscle is hard put to it to conduct the impulses. 'l'be length of the effective refractory period is not 0.20 but 0.10 of a second; it has become reduced with the rise of heart rate. The cycle is divided into two parts, a refractory plase of a tenth of a second, a responsive phase of a fiftieth of a second. 'The crest of the wave is constantly but. a fiftieth of a second belind its own walke; it travels behind it at a distance of only 10 milhimetres. We have direct and conclusive evidence that these figures may be taken as usually representative of the gap which exists; it is a minute gap, yet upon its existence the continued progress of the wave absolutely depends. To the question of this all-important gap I shall return at a later stage; it is a gap which will command the attention of many workers n the near future, for upon our power. to influence its length, our success in treating flutter and, as we shall see, the closely allied coudition fibrillation, will very largely depend. If by any means we could close that gap we could bring flutter to an abrupt termination.

\section{CARCINOMA OF THE LARGE INTESTINE.}

J. LIONEL STRETTON, M.R.C.S.,

GENIOR BURGEON, KIDDERMINSTER INIIRMARY AND CHILDRE:'S HOSPITAL.

The treatment of cases of carcinoma of the large intestine is difficult. Most patients are fond of procrastination especially in conditions where an operation enters into consideration. Time is lost with all sorts of examinations and investigations. $X \cdot r$ ry plotographs after bismuth meals, examinations and analyses of faeces, of vomit and of urine, and inspection with sigmoidoscopes often fail to reveal the early stages of carcinoma of the laige intestine, which could be found if an exploratory examination were performed. I do not deprecate these examinations. They are all links in the chain, but they should neither be spread over too long a period nor have too much weight attached to them. Multitudinous drugs are swallowed; some of them give relief by their soporific action, thereby masking symptoms and assisting the disease to progress unrecognized. Strange diets are tried, and a varied assort. ment of patent foods is consumed. Spas are visited, baths, massage, and electrical treatment are indulged in; the abdomen is sometimes rubbed with bags of shot; enemata are resorted to; sometimes a course at Plombières. All is of no avail. The progress of the disease continues until the chances of cure by a radical operation are gone.

If abdominal pain with irregularity of the bowels, which is persistent for more than twelve months, were looked upon'as sufficient to justify an exploratory operation many of these conditions would be disclosed before it is too late to eradicate them. It is very important to bear in mind that these carcinomata of the large intestine are not so likely to recur after operation as is carcinoma in other situations of the body. Provided that you can remore them during the first year or two the outlook is hopeful. I know a man working in this town now whose caecum I remófed for carcinoma on February $7 \mathrm{th}, 1911$, nearly ten years ago. He is well and strong and informs me that he

* Read before the Kidaerminster Medical Sooiety on December 3rd, can carry 2 cwt. At the time of his operation he was only 28 years of age. Professor Leith, who examined a section of the growth, reported it to be "a cubical-celled carcinoma with a few columnar cells." I hope particular notice will be taken of this man's age, because I lnow that cases are overlooked because they are " too young to have carcinom "

Then there is the question of haemorrhage. Many of these malignant cases do not show this symptom, yet it is present in many innocent conditions. There may be occult blood in the faeces, and so there may be in innocent conditions. Ballooning of the rectum is another condition which may be present in either malignant or innocent affections. These are links in the chain of evidence, but they are not strong enough to carry conviction.

The treatment I adrocate for these cases is to operate early and freely. If there is a chance to perform a radical operation for the complete removal of the growth; by all means do so. It may not be wise to do it all at one sitting. This must depend upon the case. Take, for instance. Case Ir, noted below. He was sodden with toxins, and would not have stood any lengthy operation. The obvious need was to relieve his obstiuction, to fiee him of the poisonous matter he was absorbing. The next day I was able to peiform a short-circuiting operation. Had the patient been in a good condition I should have excised the growth in the first instance.

The excision should be a free one. At least 4 in. of healthy, bowel on each side of the growth, together with the mesentery and lymphatic glands, should be removed. There is some difference of opinion as to the best method to be adopted after excising the growth. Some surgeons close the ends and then perform a lateral anastomosis. I prefer an end-to.end junction. It is true that the calibres of the cut portions of bowel may be different but that difficulty can easily be surmounted by careful suturing. The end-to-end junction is the nearest approach to Nature's arrangement, and this, I consider, should alwajs be our aim. I prefer simple suture to any mechanical appliances, and I use linen thread, which is always reliable in my hands.

Between September 28th and October 16th last I operated upon five cases of carcinoma of the large in. testine, two of them on one afternoon. When $I$ say the large intestine I do not include the rectum. The disease is not common, and it is therefore remarkable that these five cases should have presented themselves to me within eighteen days. The following are brief histories of each of these patients:

CASE I.

W. O., a male, aged 54, had suffered from pain in the rig!, side of his abdomen for twelve months. The pain was more acute at times, but the patient could not associate this with authing which might account for it. He had lost flesh, and was anaemio. An examination of the abdomen revealed a tonse globular swelling, about three inches in diameter, in the right globular awelling, about three inches in diameter, in the right hypochondriac region. - It was dull on percussion, and appeared liver. There was a right inguinal hernia, which was easily re ducible. It was thought that the swelling might be a distended gall bladder, and an exploratory operation was advised. On September 28th, 1920, under chloroform and ether, a vertical incision was made through the right rectus. The appendix was found to be thickened and inflamed, and was removed. A mass of hard carcinomatous growth was found in the hepatic flexure of the colon. It was delivered with difficulty and excised, with about four inches of the ascending colon and four of the transverse colon on either side. An end-to-end junction was made by simple suture with linen thread. En-end junction were removed with the mesentery of thead. Enlarged glands were removed with the mesentery of the colon. The patient Dctober 23 rd. His bowels act regularly, and he has no pain.

\section{Case II.}

E. T., a female, aged 45, had suffered from pain in the right hypochondriac region for more than a year. The pain was worse at times, and went through to her back. She thought she bad gall stones. On examination of the abdomen there was tenderness and rigidity in the right iliac region. The patient would not allow a full examination. It was though she might bave chronic appendicitis. On September $28 \mathrm{th}, 1920$, under chloroform and ether, I could feel a hard, irregular mass in the right iliac region, which I thought was a carcinoma the caecum. A vertical incision was made through the righ rectus. The carcinoma of the caecum was delivered ind excised, together with the enlarged glands in the mesenter 4 in. of ileum; and 4 in of ged gling colon. junction ras, and 4 in. of ascending colon. End-to-end junction was made with linen thread. I show you the specimen removed. You will notice that the growth is confined to the caecum; the appendix. was not affected. The patient made an uninterrupted recovery;"and was dischirged on
November 1st. Her bowels act regularly, and she has no pain. 


\section{Case iri.}

G. B., a male, aged 55, had suffered from pain in his right iliac region for several months, probably more than a year. He had had diffioulty in getting his bowels moved, and had lost weight. On examination of his abdomien a hard, irregular mass could be felt in the right iliac region. It was freely movable and was not tender. : It was thought to be a carcinoms of the caecum. On October 5th, 1920, under chloro form and ether, the abdomen was opened by a vertical incision through the right rectus. The caecum, which was invaded by a carcinomatous growth, was removed with its mesentery containing enlarged lymphatic glands. About 4 in. of the ileum and 4 in. of the ascending colon were removed. An end-to-end junction was made by simple suture with linen theed.to-en the specimen removed and you will notice that in this. I sho the the caecum, the appendix not being involved. The patient's after-progress wa at first satisfactory. The sutures were removed from the abdomen on October 14th, when the wound was healed, with Three days later he began to fail, and he died of exhaustion on Three days

CASE IV.

a male, aged 68, had suffered from partial obstruction of the bowels for six weeks. The obstruction had been complete for a week. He had been vomiting for two dars. The abdomon was tense and distended. Nothing could be felt. On October llth, 1920, under chloroform and ether, a vertical incision was made through the left rectus muscle. On introducing the hand, a mass of new growth (carcinoma) was felt in
the caecum. A Panl's tibe was tied into the lower end of the the caecum. A Panl's tube was tied into the lower end of th ileum and about $50 \mathrm{oz}$. of foul-smelling intestinal content drained off. The loop of intestine was fixed on the abdominal surface. The following day the patient was much improved another $50 \mathrm{oz}$. of intestinal contents having drained away durin the night. Chloroform and ether was again administered. Abou 12 in. of the small intestine was resected (including the aperturo of the Paul's tube). The distal end was closed and returned to the abdomen : the proximal end was sewn into the transverso colon by simple suture with linen thread. I was unable to bring ont the descending colon easily. The patient progressod bris or the eatisfactorily for three day's and then became weaker. His $11.45 \mathrm{p} . \mathrm{m}$. There was no peritonitis and his abdomen' was flaccid.

CASE v.

K. P., a female, aged 62 , had had complete obstruction of the bowel for three days. The abdomen was distended. She had not vomited. On October 16th, 1920, under chloroform anc ether, a vertical incision was made through the left rectus On introducing the hand, a hard, annular stricture was found in the pelvic colon. It could not be brought outside the in the pelvic colon. It could not be brought outside the abdomen. A preliminary colotomy was performed on the give relief. On the 19th the patient was again placed under an inaesthetic and the colostomy. was completed by division of the bowel. . The result is satisfactory.

You will notice that four of these cases were of the columnar type and only one of the sclerosing form. In my experience the latter is more common. Three of the cases occurred in the caecum, one in the hepatic flexure and one in the pelvic colon. In my experience the last named is more common, and it is usually of the sclerosing type. In some cases symptoms of sufficient importance are not noticed until obstruction occurs; even then the dis comfort may not be great and it is often difficult to make the patient realize the danger he is in.

I have had the opportunity of observing several cases of this condition where operation had been refused or decided against. In each instance there was a perforation in about six weels' time, accompanied by agonizing pain. One of the patients then begged me to perform an opera tion, which she had often refused previously. I washed out her peritoneum, stayed her agony, and enabled her to die in comfort. Another case I immediately relieved with an anaesthetic until the morphine had taken effect. All of these cases ruptured in the caecum.

In Case I there was a mass to be felt which appeared to be attached to his liver. His attendant, Dr. H. Miles, informed me after I had examined the case that he massaged this mass and it entirely disappeared. Perhaps if $I$ had paid more attention to this information I might have suspected a collection in the bowel, which had been forced onwards. In Case II it was the tenderness and rigidity in her right iliac region which caused the patient to seek advice. It was a question between appendix trouble and gall stones. She was too rigid to allow of a proper examination, but when she was under the anaesthetic I had no difficulty in feeling a hard mass, which I diagnosed as a carcinoma of the caecum. In Case III there was a definite hard tumour to be felt in the iliac region. It was sufficiently well defined to allow of a correct diagnosis; but the man was too fay gone for cure to be possible. In Case iv a complete obstruction for a week, with its attendant toxaemia, suggested that the obstruction was in the proximal end of the large intestine while in Case $v$ the picture pointed to a stricture in the distal portion.

The operation is a serious one and its mortality rate is high, but the alternative is either death or an artificial anus. Every case must be decided according to circumstances. I can imagine that the continuation of life for a brief period may be so imperative that a colotomy should be chosen in preference to an enterectomy. Even then the major operation might be performed at a later date. Some people, I know, would prefer death to either a colotomy or a colostomy, and there is much to be said for their view. If the growth is too extensive for removal it may be possible to perform a short-circuiting operation. This will give immediate relief without the horrors connected with an artificial anus.

I think that if the facts are put fairly before patients they will, in the vast majority of instances, accept the operation which will remove their disease, no matter what the risk. Of course, a surgeon is often placed in the position of making the decision himself. In the first two cases noted above I did not suspect the real condition, and it was not until after the patients were under the influence of the anaesthetic that I was aware of it. In neither case had I any hesitation in resecting the bowel, and both of them have made satisfactory recoveries. Perhaps they may be as fortunate as the man upon whom I operated in 1911. It depends largely upon the duration of their disease. If we are to obtain good results, we must get the cases sufficiently early.

I have already said that the onset of the disease is insidious, and that the symptoms may be slight, but I have also said :

"If abdominal pain with irregularity of the bowels, which is persistent for more than twelve months, were looked upou as sufficient to justify an exploratory operation many of these conditions would be disclosed before it is too late to eradicate them."

This is a question which is in the hands of the general practitioner rather than of the surgeon. It is he who has to watch the onset, and if he can realize the truth of $\mathrm{my}$ assertion he will be in a position to put before.his patients the advantage which may result from an exploratory operation performed before they have drifted into a condition which is beyond the stage of cure, if not of alleviation.

\section{GUNSHOT INJURY TO THE BRAIN INVOLVING BOTH CORTICAL AND SUBCORTICAL TISSUE.}

By JUDSON S. BURY, M.D.LoNd., F.R.C.P,

VISITING PHYSICIAN TO THE NEUROLOGICAL HOSPITAE FOR PENSIONERS T BRINNINGTON; CONSULTING PHYBICIAN TO THE AIANCHESTER BOYAL INFIRMARE.

THE medical profession is greatly indebted to Henry Head for his contributions to the symptomatology of disease. In his very able and philosophic writings on sensation, the outcome of many years' painstaking investigations, he has furnished us with criteria by means of which we can locate a lesion implicating any part of the afferent system, whether this be in the peripheral nerves, the spinal cord, the brain stem, the optic thalamus, the internal capsule, its afferent fibres, or the cortex. Obviously the practical value of such criteria is very great, for they enable us to determine the situation of a lesion which, from a consideration of the motor and other symptoms of a case, we may not be able to do with certainty.

In some cases, however, when more than one part of the sensory system is affected, it may be difficult to decide from an examination of sensation which part is mainly involved. Thus, in the following case $I$ have found it difficult to determine the extent to which the sensory disturbance is due to cortical or to subcortical destruiction:

Private X., aged 32, was admitted to Brinnington Hospital on June 12th, 1920. At 9 a.m. on March 10th, 1915, he was shot in the head by a rifle bullet; he felt as if his head had been hit with a stick. "He fell down, fancying "he saw little devils and that bells were ringing." He does not think he completely lost 